\title{
Adaptive resistance of apple trees in the unstable climate of southern Russia
}

\author{
Natalia Nenko $^{1 *}$, Galina Kiseleva ${ }^{1}$, Elena Ulyanovskaya ${ }^{1}$, Alla Karavaeva $^{1}$, and Tatiana \\ Shalyakho ${ }^{1}$ \\ ${ }^{1}$ Federal State Budget Scientific Institution «North Caucasian Federal Scientific Center of Horticulture, \\ Viticulture, Wine-making», 39 str.40 Let Pobedy, Krasnodar, 350901, Russia
}

\begin{abstract}
The purpose of these studies is to assess the adaptive resistance of the apple tree to winter stresses in terms of physiological and biochemical parameters, to identify the most resistant varieties for cultivation in the Krasnodar region. Objects of research are apple varieties of various origins: Orfey, Idared, Ligol, Prikubanskoe. It was found that the cryoprotective function of water-soluble sugars was maximally manifested in the varieties Orfey and Ligol, their content increased by 2.56 and 2.7 times, respectively. Soluble proteins made the greatest contribution to the formation of a protective response in Orfey and Prikubanskoye varieties in January, their content increased 1.8 and 1.9 times, respectively, compared to December. The protective function of anthocyanins was maximally manifested in December in the Orfey variety, in the bark of which their content increased by 5.6 times. Physiological and biochemical adaptation of apple varieties to low negative temperatures of the winter period is achieved by increasing the content of water-soluble sugars, proteins in anthocyanins in the bark and buds. According to the obtained data, the apple varieties Orfey and Prikubanskoye showed themselves to be more adaptive in comparison with other studied varieties and are recommended for cultivation in the Krasnodar region.
\end{abstract}

\section{Introduction}

The most important environmental factor that determines the growth and development of the apple tree is the climate. The soil and climatic conditions of the Krasnodar region are favorable for the industrial production of apple fruits with high consumer qualities, but the apple tree yield decreases as a result of the impact of winter stress factors, including those that have arisen in connection with climate change. Fluctuations of meteorological factors in the autumn-winter period lead to a decrease in adaptive properties, a loss of winter hardiness of fruit plants, including apple trees. Currently, it is important to study the physiological and biochemical characteristics of apple varieties of different origins in conditions of changing climate.

Metabolic processes occurring in plant tissues during preparation for winter are associated with the accumulation of carbohydrates, proteins, phenolic and other substances

\footnotetext{
*Corresponding author: nenko.nataliya@yandex.ru
} 
that have a protective regulatory action, which significantly increase the adaptive protective process. This process is associated with many structural, physiological, biochemical changes in plant cells [1-5], and with a change in the expression of a certain set of genes [6, 7].

There is evidence that a decrease in the amount of starch and an increase the sugar content of various plants during the winter is associated with frost resistance [8-10]. There is evidence that the content of soluble proteins in plant tissues increases during the period of autumn hardening. In the pre-winter period, specific biochemical reactions are activated in plants, newly synthesized proteins, enzymes, and isozymes appear, allowing resistant varieties to cope with unfavorable temperature conditions $[11,12]$. It has been shown that the synthesis of proteins, dehydrins, increases during hardening and, possibly, they prevent the formation of ice in plant cells [13]. The accumulation of secondary metabolites, in particular anthocyanins, in the cover tissues of shoots of various woody plants correlates with resistance to low negative temperatures [14]. Thus, the above parameters can be considered as criteria for the adaptation assessment of the apple tree to the stress factors of the winter period.

The purpose of this work is to assess the adaptive resistance of the apple tree to the stress factors of the winter period in terms of physiological and biochemical parameters, to identify the most resistant varieties for cultivation in the Krasnodar region and for use in breeding.

\section{Materials and methods}

Objects -4 varieties of apple trees:

- Orfey is a winter ripening variety of NCFSCHVW breeding, differs in restrained growth, immunity to scab, frost resistance, drought resistance, early maturity. The variety on the rootstock M9 begins to bear fruit on second year of planting. Fruits reach a mass of $220 \mathrm{~g}$.

- Idared - a winter ripening variety of American breeding. It is characterized by medium winter hardiness, high drought resistance, not resistant to scab. Variety enters fruiting on medium-sized rootstocks on fifth-sixth year of planting. Fruiting is regular. Idared variety is the control.

- Ligol - a winter ripening variety of Polish breeding, which differs in high productivity, early fruiting, sufficient winter hardiness, resistance against scab, prone to periodicity of fruiting.

- Prikubanskoye - a winter ripening variety of NCFSCHVW breeding. Drought resistance is high, frost resistance is above average, relatively resistant to scab. The variety begins fruiting on third-fourth year of planting. Fruits reach a weight of 210-250 g.

The novelty of the study is as follows: the Orfey variety is studied for the first time in terms of physiological and biochemical parameters, for other varieties, these studies will help to identify trends in the implementation of the adaptive capabilities of varieties in a changing climate.

The indicators of the water regime were determined by the gravimetric method and were expressed in $\%$ of the wet weight. The content of soluble sugars was determined using an anthrone reagent according to the method [15]. The content of soluble proteins was determined using a Unico 2800 spectrophotometer [16]. All studies were carried out on the instrumentation of the Center of Collective Using of Technological Equipment in the following areas: genomic and post-genomic technologies, physiological, biochemical and microbiological studies; soil, agrochemical and ecotoxicological research; food safety.

\section{Results and discussion}

In autumn, a decrease in the water content of the tissues of apple tree shoots is due to a decrease in the activity of metabolic processes in connection with the entry into winter 
dormancy. In our studies in November, differences in the water content of the buds (total water content) of various apple varieties were revealed. The total water content varied from $34.11 \%$ for the Idared variety to $45.09 \%$ for the Orfey variety. No significant changes in the total water content in the buds of the studied apple varieties were observed during the winter. Stable values of the water content of the buds were maintained during the winter period.

Of great importance in the resistance of plants to unfavorable winter conditions is the ratio between the fractions of water (free and bound), which determines the degree of its mobility within the cell. In the process of hardening, the content of the bound form of water increases, which makes it resistant to winter stresses. High values of the ratio of bound to free forms of water indicate an increased resistance of the variety.

In our studies in November, the highest ratio of bound and free forms of water (3.00) was observed in variety Ligol, in other varieties it was 2.31-2.56. In December-February, in the Ligol variety, it almost did not change and amounted to 3.32-3.56. For the rest of the studied varieties, this coefficient was higher during the winter and had values of 4.01-4.58. The highest coefficients of the ratio of bound and free water fractions (4.56-4.58), indicating resistance in winter, were observed in the varieties Orfey, Prikubanskoe (Fig. 1).

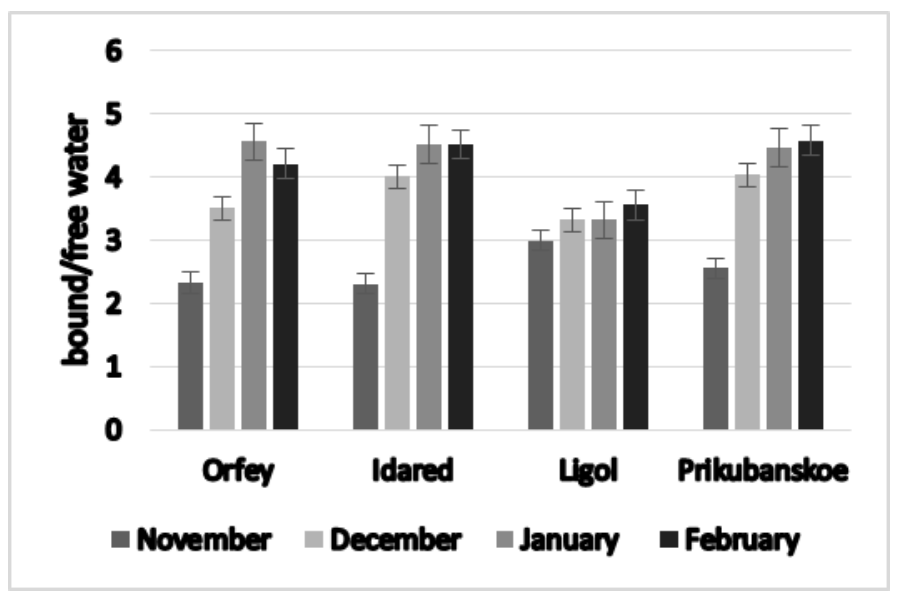

Fig. 1. The ratio of bound and free water in apple buds in the autumn-winter period 2018-2021 (average values). $\operatorname{LSD}_{0.5}$ : November - 1.45; December - 2.27; January - 2.51; February -2.17.

It is known that sugars have the properties of cryoprotectant, and an increase in their content in plants is associated with frost resistance. Sugars protect proteins from denaturation during dehydration and also prevent ice formation inside cells. There is evidence that the hydrolysis of starch and the accumulation of water-soluble sugars (sucrose, glucose, fructose) in the cytoplasm under the action of low temperatures increases in frost-resistant varieties of woody and herbaceous plants [8-10]. In our studies, in the pre-winter period, in November, the smallest amount of water-soluble sugars was accumulated in the Ligol variety -5.52 $\mathrm{mg} / \mathrm{g}$ dry weight, in other varieties it was $8.31-12.47 \mathrm{mg} / \mathrm{g}$ dry weight (Fig. 2). 


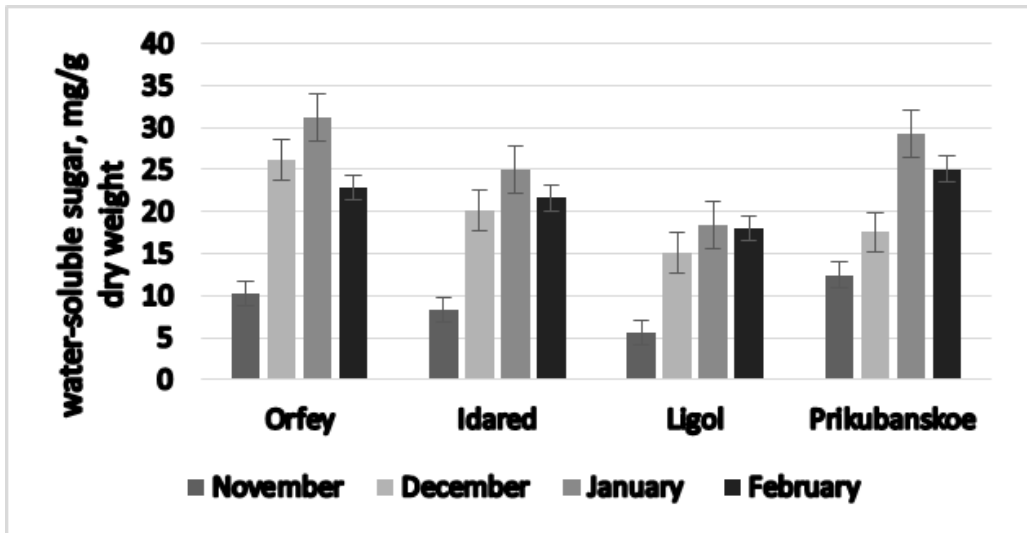

Fig. 2. Dynamics of the content of water-soluble sugars in the bark of an apple tree in the autumnwinter period 2018-2021 (average values). LSD 0.5 : November - 1.44; December - 2.71; January 2.23; February -1.49

In December, as a result of starch hydrolysis, their content increased, with the maximum in Orfey variety -2.56 times and in Ligol variety -2.7 times. In January, the content of water-soluble sugars increased in comparison with December by 1.1-1.6 times, depending on the variety; in February, it decreased for all varieties by 1.01-1.3 times, depending on the variety. Consequently, the cryoprotectant function of sugars was maximally manifested in all varieties in December.

When studying winter hardiness, special attention is paid to proteins due to their hydrophilic properties. In our studies, it was found that by November all studied apple varieties accumulated from 4.36 to $4.90 \mathrm{mg} / \mathrm{g}$ dry weight of soluble proteins, depending on the variety (Fig. 3).

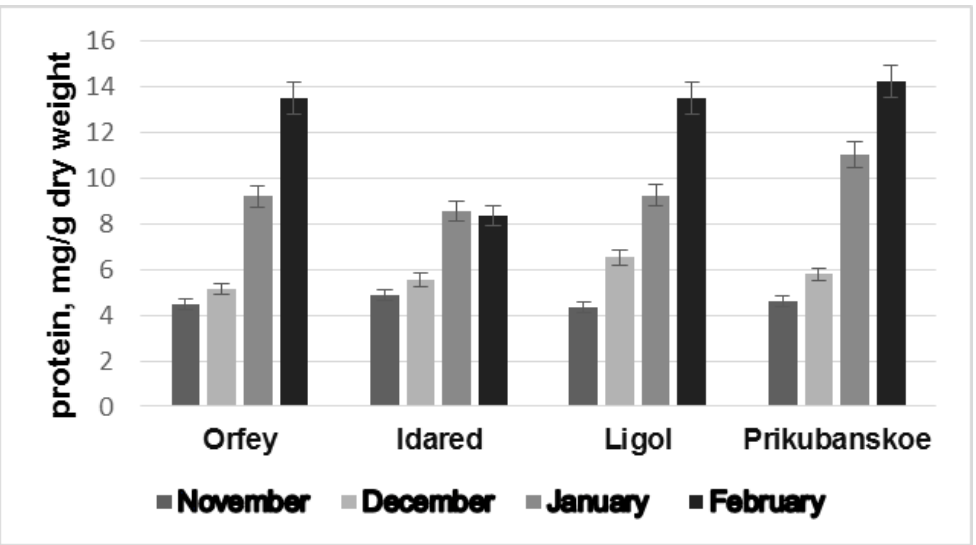

Fig. 3. Dynamics of the content of soluble proteins in apple buds in the autumn-winter period 20182021 (average values). LSD 0.5 : November - 4.92; December - 2.22; January - 4.65; February - 5.33.

In December, due to a decrease in temperature, the protein content of the Ligol variety increased by 1.5 times, and in the other varieties - by 1.1-1.2 times. In the following months of the winter period, the protein content increased in all varieties in response to stress by 1.31.9 times, depending on the variety. Low-molecular-weight protein compounds made the greatest contribution to the formation of the protective response in the Orfey and Prikubanskoye varieties in January, when their content increased 1.8 and 1.9 times, respectively, compared to December. It is known that anthocyanins are associated with an 
increase in resistance plants for cooling and freezing, the integumentary tissues of some winter-hardy plants contain high concentrations of anthocyanins. In addition to this function, anthocyanins and chalcones are components of the antioxidant defense, protecting the body from oxidative stress [14]. In our studies in November, the content of anthocyanins in the bark of the studied apple varieties was 4.5-7.3 c.u. (fig. 4).

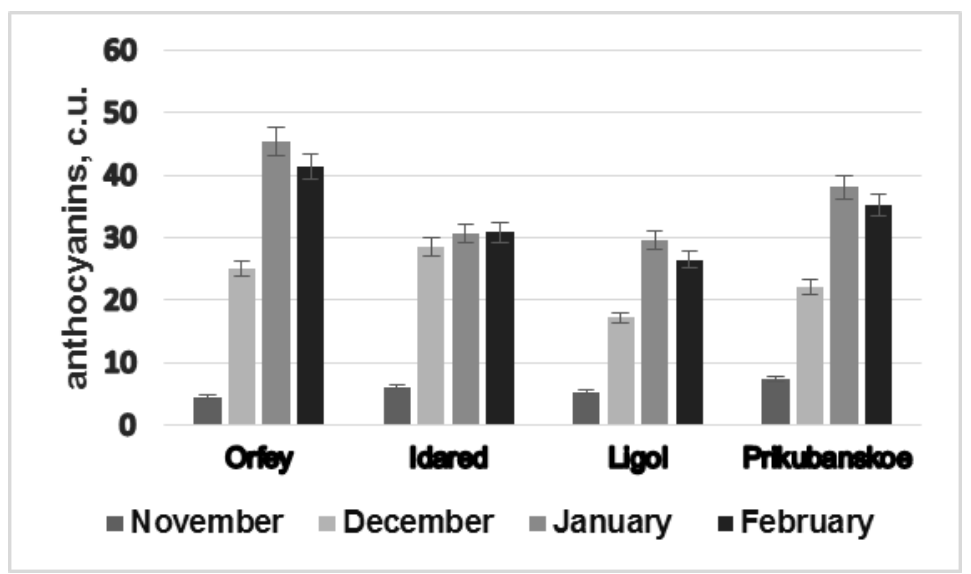

Fig. 4. Dynamics of the content of anthocyanins in the bark of an apple tree in the autumn-winter period 2018-2021 (average values). LSD 0.5 : November - 21.92; December - 14.13; January - 12.89; February - 16.62 .

During December and January, the content of anthocyanins increased significantly in response to low temperatures: in December, 3.0-5.6 times; in January - 1.07-1.8 times, depending on the variety. The protective function of anthocyanins was most pronounced in the Orfey variety in December, where an increase in their content by 5.6 times was observed in comparison with November. In February, the content of anthocyanins in the bark of all studied varieties decreased slightly - by 1.07-1.11 times, due to the termination of their synthesis.

\section{Conclusion}

The research of apple varieties on the parameters of the water regime, the content of watersoluble sugars, soluble proteins, anthocyanins was carried out during the winter periods of 2018-2021. It was revealed that the studied apple varieties in the unstable climate of southern Russia implement a similar mechanism for the formation of winter hardiness, which has quantitative differences in the content of some metabolites in the pre-winter and winter periods. Physiological and biochemical adaptation of apple varieties to the low temperatures of the winter period is achieved by increasing the fraction of bound water in the total water content, increasing the content of water-soluble sugars and proteins in anthocyanins in hibernating organs. It was found that the apple varieties Orfey and Prikubanskoye proved to be more adaptive in comparison with other studied varieties in the conditions of the prewinter and winter periods and are recommended for cultivation in the Krasnodar region.

\section{References}

1. R. Arora, K. Taulavuori, Front. Environ. Sci., 4, 44-51 (2016) https://doi.org/10.3389/fenvs.2016.00044 
2. D. Wu, S. Kukkonen, J. Luoranen, P. Pulkkinen, J. Heinonen, A. Pappinen, T. Repo, Sci. Hortic., 258, 108755 (2019) https://doi.org/10.1016/j.scienta.2019.108755

3. R. Arora, L.J. Rowland, HortScience, 46(8), 1070-1078 (2011) https://doi.org/10.21273/HORTSCI.46.8.1070

4. A. Theocharis, C. Clement, E.A. Barka, Planta, 235, 1091-1105 (2012) https://doi.org/10.1007/s00425-012-1641-y

5. L.V. Gusta, M. Wisniewski, Physiol. Plant., 147 (1), 4-14 (2013) https://doi.org/10.1111/j.1399-3054.2012.01611.x

6. T.S. Artlip, M.E. Wisniewski, R. Arora, J. Norelli, Hort. Res., 3, 16006 (2016) https://doi.org/10.1038/hortres.2016.6

7. M. Wisniewski, J. Norelli, T. Artlip, Front. Plant Sci., 6, 85, (2015) https://doi.org/10.3389/fpls.2015.00085

8. H. Karami, M. Rezaei, A. Sarkhosh, M. Rahemi, M. Jafari, Gesunde Pflanzen, 70, 195203 (2018) https://doi.org/10.1007/s10343-018-0431-2

9. M.M. Peixoto, P.C. Friesen, R.F. Sage, J. Exp. Bot., 66(14), 4415-4425 (2015) https://doi.org/10.1093/jxb/erv093

10. R. John, N.A. Anjum, S.K. Sopory, N.A. Akram, M. Ashraf, Biol. Plant., 60, 603-618 (2016) https://doi.org/10.1007/s10535-016-0648-9

11. M. Maleki, M. Ghorbanpour, In: S.H. Wani (ed.) Biochemical, Physiological and Molecular Avenues for Combating Abiotic Stress in Plants, 57-71 (Academic Press, 2018) https://doi.org/10.1016/B978-0-12-813066-7.00004-8

12. Y.X. Wang, Ya HU, B.H. Chen, Y.F. Zhu, M.M. Dawuda, S. Svetla, 17(4), 857-866 (2018) https://doi.org/10.1016/S2095-3119(17)61760-X

13. P. Haimi, J. Vinskienė, I. Stepulaitienė, D. Baniulis, G. Stanienė, J.B. Šikšnianienè, R. $\begin{array}{lllll}\text { Rugienius, J. Plant } \quad \text { Physiol., 218, } & \text { 175-181 }\end{array}$ https://doi.org/10.1016/i.jplph.2017.08.008

14. D.F. Holderbaum, T. Kon, M.P. Guerra, Sci. Hortic., 168, 58-63 (2014) https://doi.org/10.1016/j.scienta.2014.01.020

15. A. Ershadi, R. Karimi, K.M. Naderi, Acta Physiol. Plant., 38, 2 (2016) https://doi.org/10.1007/s11738-015-2021-6

16. Ö. Kaya, C. Köse, Acta Physiol. Plant., 39, 209 (2017) https://doi.org/10.1007/s11738$\underline{017-2513-7}$ 